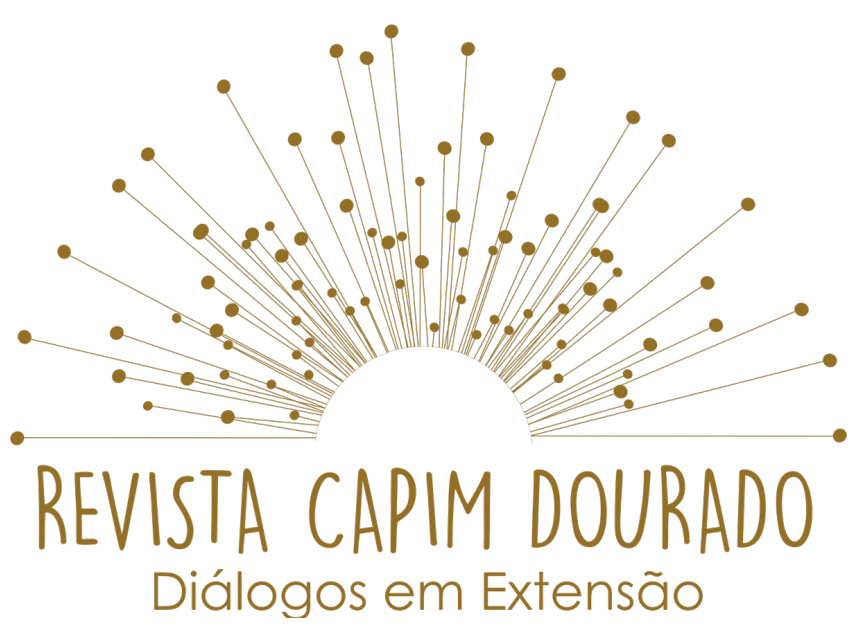

ISSN n² 2595-7341

Vol. 3, n. 2, Maio-Agosto, 2020

DOI: http://dx.doi.org/10.20873/uft.2595-7341.2020v3n2p90

\title{
SER EM TEMPOS DE COVID-19: um relato de experiência de pesquisa e extensão no Departamento de Serviço Social da Universidade de Brasília
}

BEING IN COVID TIMES-19: an account of research and extension experience in the Department of Social Service at the University of Brasilia

BEING IN COVID TIMES-19: relato de la experiencia de investigación y extensión en el Departamento de Servicio Social de la Universidad de Brasilia

\author{
Hayeska Costa Barroso ${ }^{1}$ \\ Anabelle Carrilho da Costa ${ }^{2}$ \\ Larissa Araújo Matos ${ }^{3}$ \\ Leonardo Rodrigues de Oliveira Ortegal ${ }^{4}$ \\ Taise Cristina Gomes Clementino de Negreiros ${ }^{5}$ \\ Thaís Kristosch Imperatori ${ }^{6}$
}

\footnotetext{
${ }^{1}$ Doutora do curso de Licenciatura em Sociologia da Universidade Federal do Ceará (UFC), Tocantins, hayeskacb@gmail.com

2 Doutora do curso de Licenciatura Política Social da Universidade de Brasília, UnB, Brasil, anabelle.carrilho@unb.br

${ }^{3}$ Mestra do curso de Licenciatura Psicologia da Universidade Federal do Pará, UFPA, Brasil. Larissamattos@hotmail.com.

${ }^{4}$ Doutor do curso de Licenciatura Política Social da Universidade de Brasília, UnB, Brasil, ensejo@gmail.com.

${ }^{5}$ Mestra do curso de Licenciatura em Serviço Social da Universidade Federal do Rio Grande do Norte, UFRN, Brasil, taise.negreiros@unb.br

${ }^{6}$ Doutora em Política Social pela (UnB). Professora do Departamento de Serviço Social da Universidade de Brasília. Pesquisadora do Grupo de Estudos e Pesquisas sobre Democracia, Sociedade Civil e Serviço Social (GEPEDSS). thaisimperatori@unb.br
} 


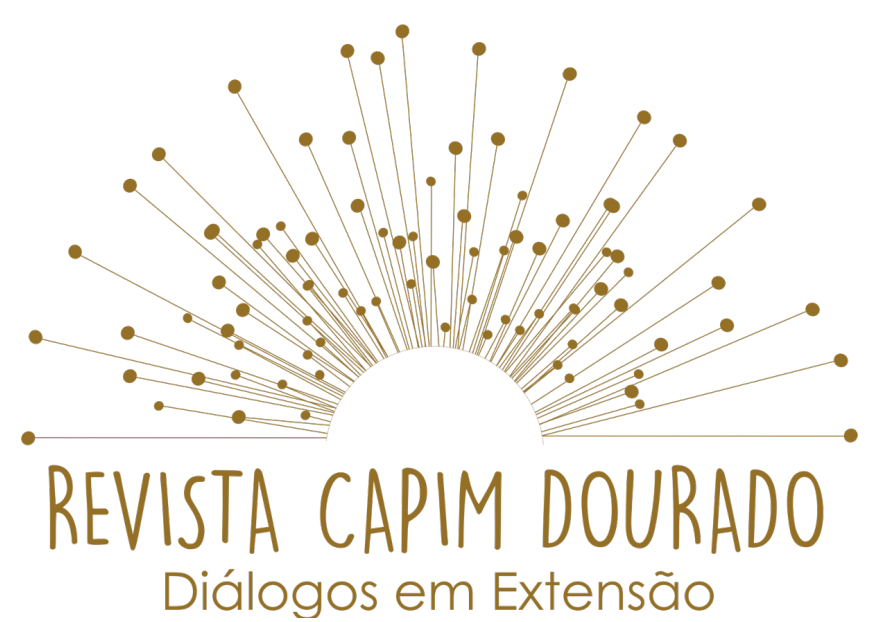

ISSN n² 2595-7341

Vol. 3, n. 2, Maio-Agosto, 2020

DOI: http://dx.doi.org/10.20873/uft.2595-7341.2020v3n2p90

\section{RESUMO}

Este artigo versa sobre o projeto de pesquisa e extensão "SER em tempos de COVID 19" cujos objetivos são: socializar os dados da pesquisa sobre os desafios vivenciados pelas/os discentes do curso de Serviço Social da UnB durante a suspensão das atividades acadêmicas; construir um canal de comunicação entre o departamento, docentes e discentes e; socializar informações da universidade e produções teóricas dos/as docentes do departamento sobre o contexto de pandemia.

PALAVRAS-CHAVE: Serviço Social, Universidade, COVID-19.

\section{ABSTRACT}

This article is about the research and extension project "SER em tempo de COVID19" whose objectives are: to socialize the research data on the challenges experienced by the students of the UNB Social Work course during the suspension of academic activities; build a communication channel between the department, teachers and students and; socialize university information and theoretical productions of the department's professors about the pandemic context.

KEYWORDS: Social Work; University; COVID-19

\section{RESUMEN}

Este artículo trata sobre el proyecto de extensión "SER em tempo de COVID-19" cuyos objetivos son: socializar los datos de investigación sobre los desafíos experimentados por los estudiantes del curso de Trabajo Social de la UNB durante la suspensión de actividades académicas; construir un canal de 


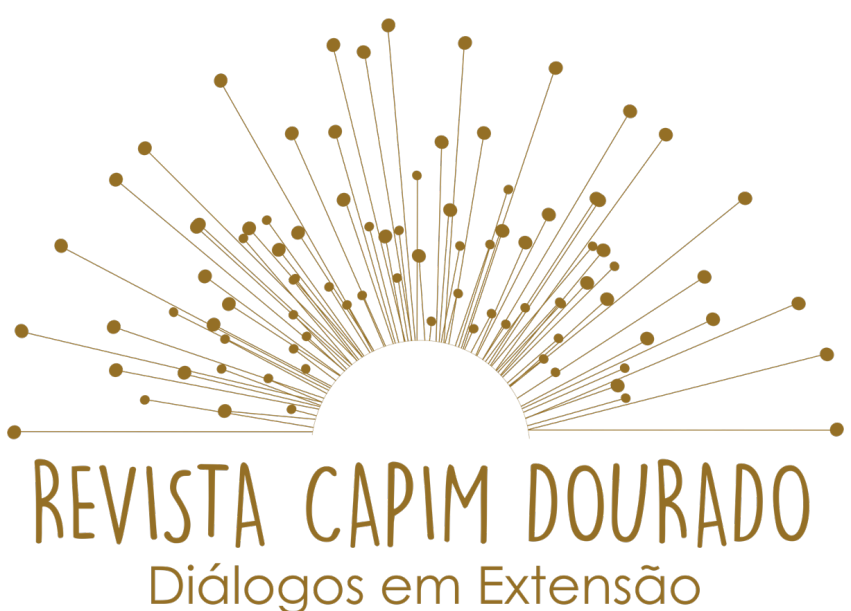

ISSN n० 2595-7341

Vol. 3, n. 2, Maio-Agosto, 2020

DOI: http://dx.doi.org/10.20873/uft.2595-7341.2020v3n2p90

comunicación entre el departamento, profesores y alumnos y; socializar la información universitaria y las producciones teóricas de los profesores del departamento sobre el contexto de la pandemia.

PALABRAS CLAVE: Trabajo Social; Universidad; COVID-19.

Recebido em: 31.03.2020. Aceito em: 19.04.2020. Publicado em: 30.05.2020. 


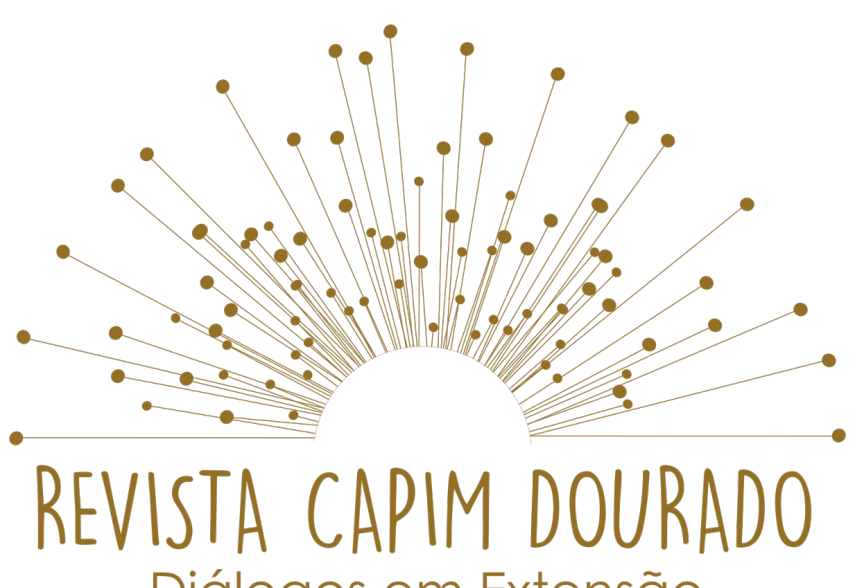

\section{Diálogos em Extensão}

ISSN n² 2595-7341

Vol. 3, n. 2, Maio-Agosto, 2020

DOI: http://dx.doi.org/10.20873/uft.2595-7341.2020v3n2p90

\section{Introdução}

As primeiras medidas de enfrentamento à pandemia de COVID-19 no Distrito Federal - DF ocorreram no dia 11 de março, quando havia o registro de 74 casos suspeitos e apenas dois confirmados. Por meio do Decreto 40.509/2020, que dispôs sobre as medidas para enfrentamento da emergência de saúde pública de importância internacional decorrente do novo coronavírus, o governador do DF suspendeu, inicialmente pelo prazo de cinco dias, "atividades educacionais em todas as escolas, universidades e faculdades, das redes de ensino pública e privada". Esta medida tinha como objetivo estabelecer um distanciamento social inicial, enquanto outras medidas ainda estavam em discussão.

No mesmo dia, o Conselho de Ensino, Pesquisa e Extensão - CEPE da Universidade de Brasília - UnB decidiu suspender as atividades acadêmicas presenciais na instituição, como aulas, palestras, seminários e colações de grau. Na ocasião, o Comitê do Plano de Contingência do COVID-19 na UnB reconheceu os impactos decorrentes do Decreto para a sociedade do DF e a comunidade universitária. No dia 11 de março, foi publicado Ato da Reitoria n 392/2020, que suspendeu atividades administrativas presenciais na Universidade. Tais medidas ocorreram na primeira semana do período letivo, iniciado em 9 de março do corrente ano.

Diante do avanço da doença, o referido Decreto distrital foi renovado diversas vezes. No âmbito da UnB, o CEPE, em reunião realizada em 23 de março, deliberou por "suspender o calendário acadêmico da Universidade de Brasília do 


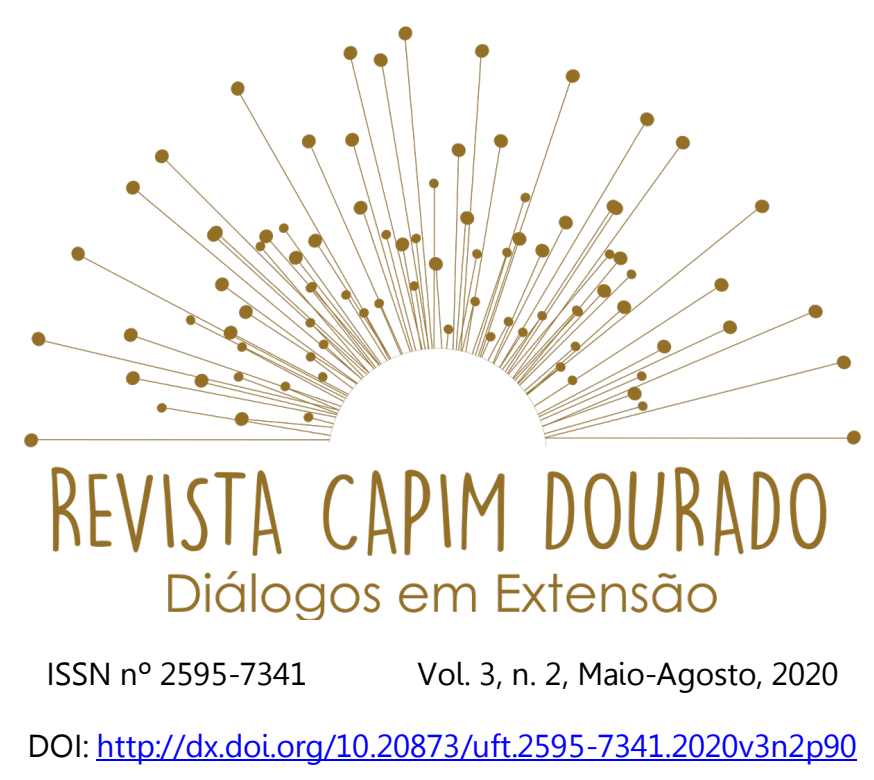

primeiro semestre letivo de 2020, pelo tempo que perdurasse a situação de emergência em saúde pública decorrente da pandemia de coronavírus (COVID19) no Distrito Federal". A medida, ainda vigente, aplica-se tanto à graduação quanto à pós-graduação. Ficaram autorizadas atividades de estágio supervisionado e assistência apenas na área de saúde, preferencialmente relacionadas ao combate à COVID-19; bancas de trabalho de conclusão de curso, qualificação e defesa de dissertação e tese, de modo não presencial; e atividades de extensão para o atendimento à comunidade, preferencialmente à distância e em temas relacionados à saúde.

Complementar a esta Resolução, em 26 de março, o Decanato de Ensino de Graduação divulgou a Circular no 9/2020, na qual apresentou orientações administrativas a serem seguidas pelas Unidades Acadêmicas e recomendou a promoção de iniciativas de combate à propagação da COVID-19 com participação voluntária de discentes.

\section{Metodologia}

Diante do cenário anteriormente citado, a gestão do Departamento de Serviço Social - SER consultou o corpo docente sobre a viabilidade de construção de um grupo de trabalho visando elaborar estratégias a serem desenvolvidas junto aos/às seus/suas discentes no período de suspensão do calendário acadêmico. Assim, foi constituído o Grupo de Trabalho - GT, com o objetivo de identificar as demandas e os desafios vivenciados pelos/as discentes do Curso de Serviço Social da UnB durante o período de suspensão das atividades acadêmicas e distanciamento social, e, a partir dos resultados identificados, propor iniciativas, 


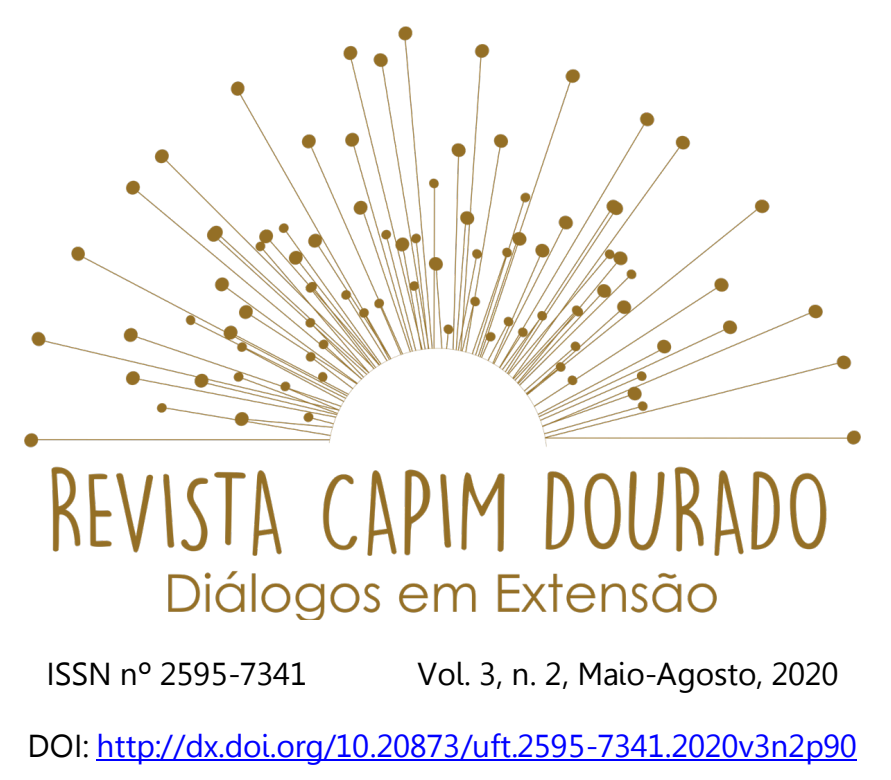

por meio de ações e/ou atividades de apoio acadêmico e pedagógico, bem como pensar em propostas por meio das quais a universidade pudesse contribuir para o enfrentamento coletivo no contexto de pandemia. O GT conta com participação de seis docentes, que constituem os/as autores/as do presente artigo.

A primeira ação proposta pelo GT foi a realização de uma pesquisa, a ser aplicada junto ao corpo discente. Partiu-se da compreensão de que as medidas de distanciamento social exigiram a adoção de diversas mudanças na rotina diária de trabalho e estudo, sendo necessário compreendê-las para posterior proposição de estratégias de apoio acadêmico e pedagógico ao corpo discente.

A metodologia da referida pesquisa contou com a elaboração de um questionário constituído de 33 perguntas, divididas em três blocos temáticos, a saber: dados sociodemográficos; vivência dos/as discentes no contexto da pandemia; e formação profissional e acadêmica em tempos de distanciamento social. Para fins de coleta de dados, o instrumento foi desenvolvido em formato online, por meio do Google Forms, sendo disponibilizado para respostas no período de 01 a 07 de abril de 2020.

\section{Principais resultados alcançados}

Os resultados apontaram que 339 formulários foram respondidos por discentes, o que representou quase $50 \%$ da totalidade de estudantes do Departamento. Destacam-se alguns dados socioeconômicos, dentre os quais: $85,8 \%$ possuem até 24 anos de idade; $81,1 \%$ afirmaram ser do gênero feminino, seguindo uma tendência histórica da profissão; $45,9 \%$ se autodeclararam brancos, seguido por $30,2 \%$ pardos e $19,5 \%$ pretos (somando $49,7 \%$ de alunos/as 


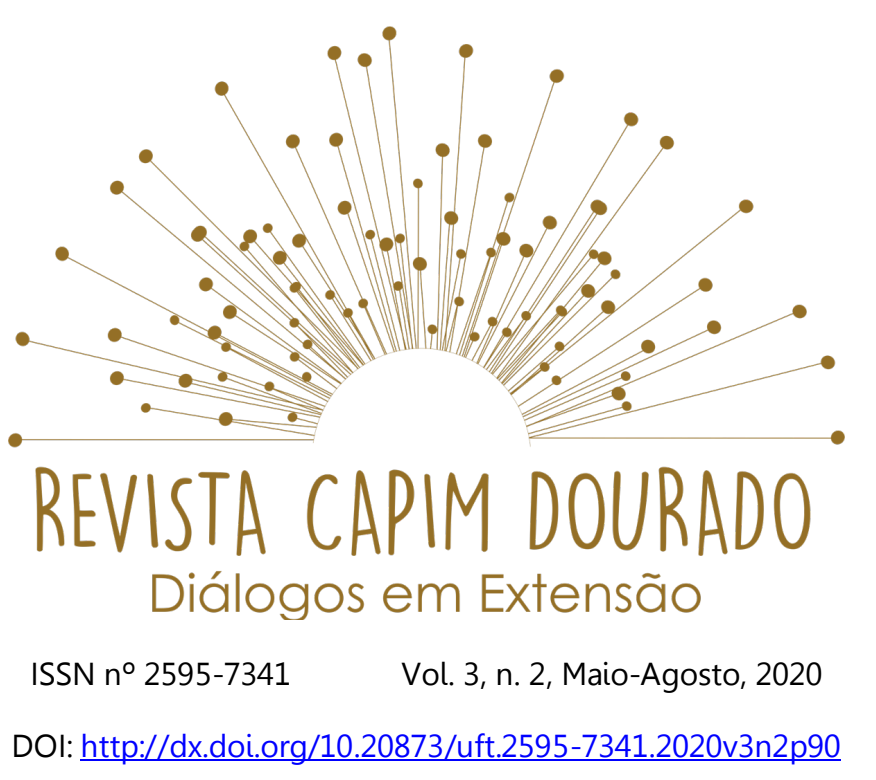

autodeclarados negros); apenas 7\% informaram ter filhos; 76,4\% residem em cidades satélites do DF; $91,5 \%$ declararam residir com familiares; $61,8 \%$ não realizam atividades remuneradas; $28,6 \%$ são beneficiários de programas de assistência estudantil da UnB, dos quais, metade participa do Programa Bolsa Alimentação.

Em relação a algumas questões de saúde, no início da pandemia, 68,7\% afirmaram não ser grupo de risco para COVID-19, ao passo que $62,8 \%$ declararam residir com alguém que é grupo de risco para a doença. 90,6\% afirmou não possuir assistência psicológica e/ou psiquiátrica profissional durante o período de distanciamento social. Isso não significa, porém, o desinteresse por tal serviço, uma vez que $57,3 \%$ informaram que gostariam de ter esse atendimento e $27,4 \%$ responderam talvez.

No eixo formação profissional e acadêmica, identificou-se que $29,9 \%$ continuam realizando atividades relacionadas ao curso de Serviço Social mesmo com a suspensão das atividades acadêmicas, principalmente aquelas relacionadas ao Trabalho de Conclusão de Curso e leitura de textos de disciplinas cursadas em semestres anteriores ou sugeridos por docentes no início do $1^{\circ}$ semestre de 2020.

Na pesquisa também buscou-se identificar quais as principais fontes de informação sobre a UnB no atual cenário, sendo informado que 82,3\% utilizam redes sociais, seguido por acesso ao site institucional da Universidade, 46,3\%, e e-mail pessoal, 33,3\%. Ademais, $64,95 \%$ dos/as estudantes sugeriram a disponibilização de canal online com dicas e sugestões temáticas relacionadas ao Serviço Social, bem como $57,7 \%$ sugeriu a estratégia de vinculação de 


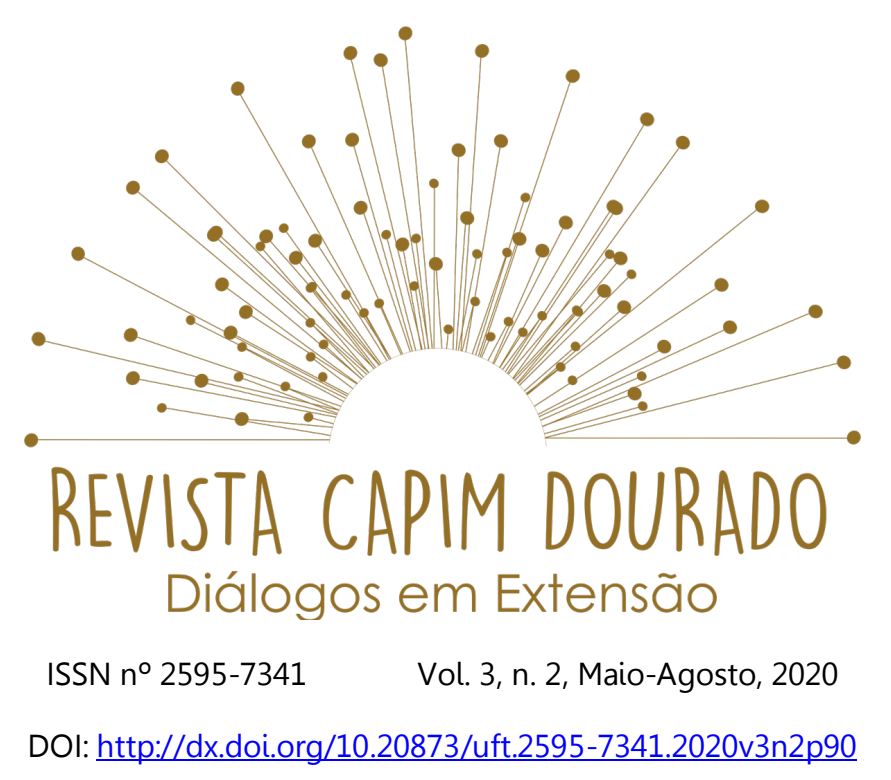

informações e notícias. Entre os canais mais utilizados, o e-mail se mostrou como uma ferramenta viável e de fácil acesso.

Uma das iniciativas decorrentes dos resultados da primeira fase da pesquisa, foi a criação do Boletim "SER em tempos de COVID-19", com textos inéditos destinados à publicação, além de ser um espaço de troca de informações e conexão com a comunidade estudantil, docente e técnica do SER/UnB. O Boletim quinzenal, que se encontra em sua quarta edição, foi construído a partir das seguintes seções: 1. "Sobre o COVID-19", no qual são apresentados dados sobre a realidade brasileira e orientações sobre medidas de prevenção à doença, bem como pesquisas diversas; 2. "Resultados da pesquisa" que visa dar uma devolutiva aos participantes e informar os/as demais docentes e técnicosadministrativos sobre essa realidade; 3. "UnB e suspensão do semestre", visando informar a comunidade do SER sobre as medidas institucionais adotadas quanto à suspensão do semestre, bem como ações desenvolvidas pela Universidade nas áreas de pesquisa, extensão e assistência estudantili 4. "Serviço Social e COVID$19 "$ ", no qual são tratados os desafios vivenciados por assistentes sociais no contexto da pandemia, bem como as expressões da questão social que se intensificaram nesse período; 5. "Políticas sociais em tempos de pandemia", com o objetivo de abordar particularidades e desafios apresentados às políticas sociais setoriais no atual contexto; e 6. "Para se distrair", com sugestões de filmes, séries, livros, podcasts, cursos online, entre outros.

O Boletim é divulgado aos/às discentes por correio eletrônico e disponibilizado no site do Instituto de Ciências Humanas da UnB. Tem-se aí o 


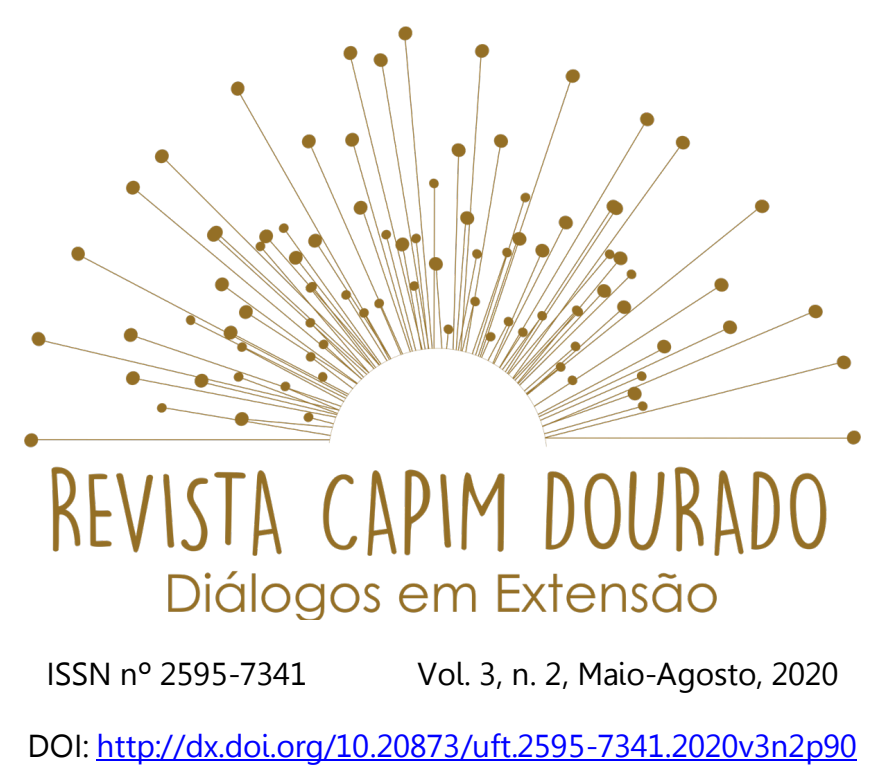

desafio de promover a comunicação entre a comunidade do SER em tempos de suspensão de atividades acadêmicas.

Desde as primeiras ações de enfrentamento ao COVID-19 já se passaram mais de três meses, com aumento do número de casos e de mortes, que já ultrapassam 50 mil em todo o Brasil. Estamos, em um novo momento da pandemia. $\mathrm{Na}$ UnB, começa-se a debater possibilidades de retorno às atividades acadêmicas, sobretudo por meio de ensino remoto, e são problematizadas questões como a garantia de acesso a todos os/as estudantes e os limites do ensino remoto para a formação crítica dos discentes.

Diante disto, o Boletim "SER em tempos de COVID-19" tornou-se o projeto de pesquisa e extensão "SER em tempos de COVID-19", aprovado na Segunda Chamada Prospectiva de Propostas de Projetos e Ações de Pesquisa, Inovação e Extensão para o combate à COVID-19, realizada pelo Decanato de Pesquisa e Inovação e o Decanato de Extensão da UnB, em conjunto com o Comitê de Pesquisa, Inovação e Extensão de combate à COVID-19.

Ocorrerão ainda outras duas fases no projeto, com uma nova aplicação de questionários online, de modo a produzir dados sobre a realidade do corpo discente do SER durante o período de suspensão das atividades acadêmicas em uma série histórica, bem como o surgimento de novas demandas.

A segunda fase da pesquisa se encontra em fase de coleta de dados durante a última semana de junho de 2020, contendo, para além de perguntas da primeira etapa, uma seção sobre a retomada das atividades acadêmicas e uma seção de avaliação do Boletim. Esta última seção, em especial, será importante 


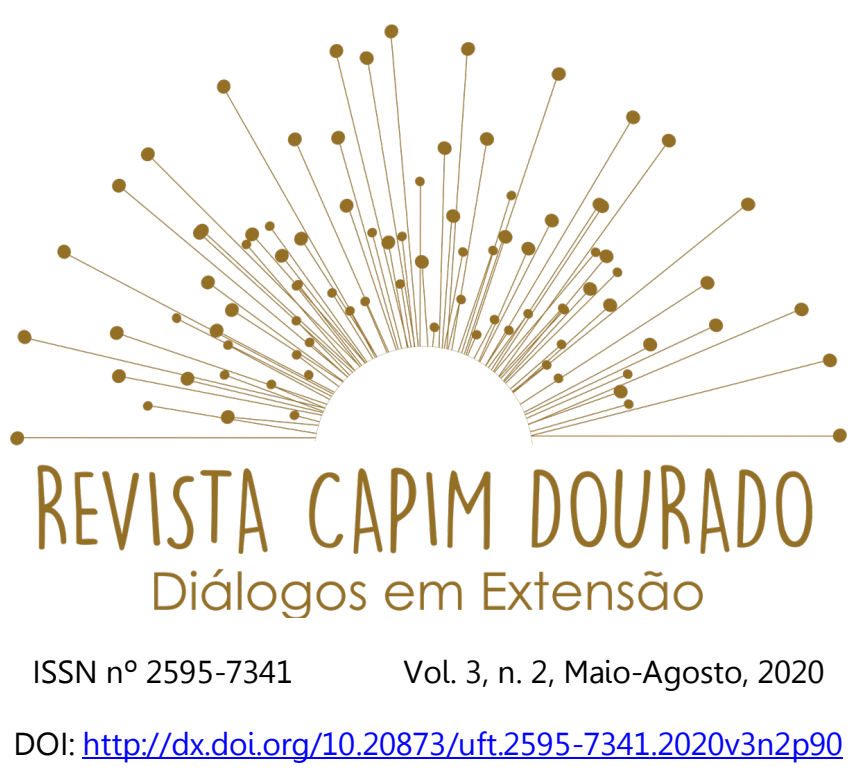

para identificar pontos negativos e positivos apontados pelo público em relação ao Boletim.

\section{Considerações finais}

A experiência de pesquisa e extensão apresentada está em andamento, entretanto, os resultados preliminares da primeira fase do questionário já mostram a importância do contato entre corpo docente, discente e técnicoadministrativo para levantamento e análise de situações de risco de diversas naturezas perante a pandemia. Essa identificação prévia é requisito para a proposição de ações críticas que levem em consideração a realidade social. É urgente pensar as transformações que serão exigidas no âmbito da formação e intervenção profissionais em Serviço Social, de modo a não perder de vista o compromisso ético-político previsto nos documentos legais e normativos que regem a profissão. Essas transformações apenas poderão ser pensadas coletivamente pela categoria e futuros profissionais, levando em consideração as dimensões teórico-metodológica, técnico-operativa, ético-política e investigativa, que, juntas, conformam o arcabouço crítico que permite a intervenção na realidade social. Compreender a atual conjuntura de adoecimento e morte, que atinge, sobretudo e frontalmente, a população pobre, negra e periférica do país, escancarando e aprofundando desigualdades estruturantes da sociedade capitalista brasileira, é instrumento básico e central para o Serviço Social. Os/as estudantes do curso, num contexto universitário mais inclusivo nas últimas décadas, compõem uma amostra primordial desta análise. 


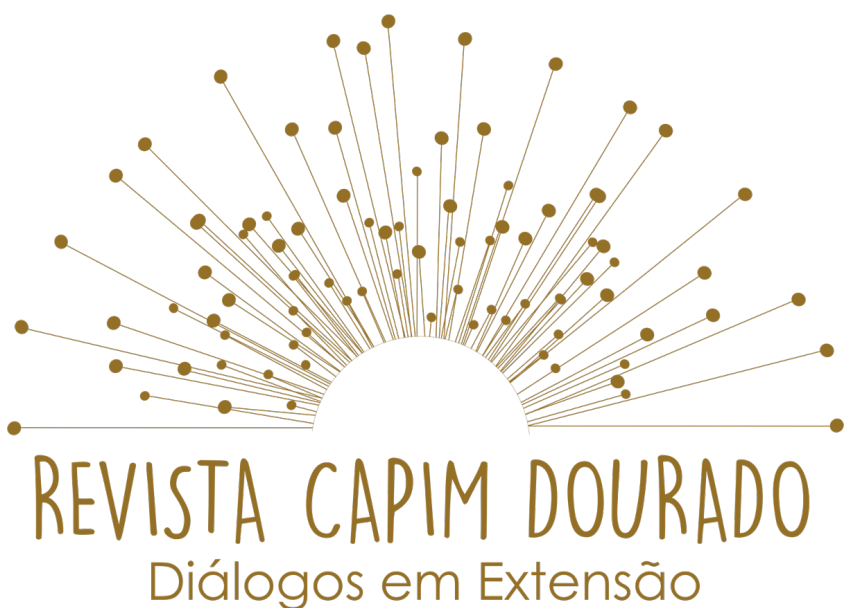

ISSN n० 2595-7341

Vol. 3, n. 2, Maio-Agosto, 2020

DOI: http://dx.doi.org/10.20873/uft.2595-7341.2020v3n2p90

\section{Referências}

DISTRITO FEDERAL. Decreto 40.509/2020, que dispôs sobre as medidas para enfrentamento da emergência de saúde pública de importância internacional decorrente do novo Coronavírus. 2020.

UnB. Ato da Reitoria no 392/2020, que suspendeu atividades administrativas presenciais na Universidade. Tais medidas ocorreram na primeira semana do período letivo, iniciado em 9 de março do corrente ano. 2020. 